\title{
Age-related differences in familiarity and recollection: ERP evidence from a recognition memory study in children and young adults
}

\author{
DANIELA CZERNOCHOWSKI, AXEL MECKLINGER, MIKAEL JOHANSSON, \\ and MICHAEL BRINKMANN \\ Saarland University, Saarbrücken, Germany
}

\begin{abstract}
Using event-related potentials (ERPs), we examined the relative contributions of familiarity and recollection to recognition memory for items and their study contexts in school-aged children and adults. Whereas adults were able to selectively accept target items and to reject familiar nontarget items in an exclusion task, this discrimination was more difficult for children, as was evident in the high false alarm rates to nontargets even when item memory was controlled for. The analysis of the adults' ERPs revealed more flexible and task-appropriate retrieval mechanisms, as was evident in the correlates of familiarity, recollection, and nontarget retrieval, as well as in postretrieval evaluation. In contrast, children's ERPs revealed a parietal old/new effect for targets taken as a putative correlate of recollection. These findings suggest that children rely predominantly on recollection during recognition judgments, even in the absence of efficient memory control processes. The latter processes enable adults to monitor and verify the retrieved information and to control nontarget retrieval in the service of adequate source memory performance.
\end{abstract}

In many everyday situations, recognition memory can be accomplished via judgments of an event's familiarity or novelty. For example, seeing a person in an atypical setting may evoke a feeling of familiarity. We know that we have seen this person before, without remembering the circumstances of these previous encounters. Memory judgments in laboratory tasks that require discrimination between items previously presented and new items can be accomplished by relying on an item's familiarity that builds up as a function of repeated exposure. Conversely, in other situations, successful memory requires the retrieval of an item, as well as the context of its prior occurrence, as in a situation in which we have to decide whether we previously have seen someone in Setting A or Setting B. In the laboratory, these types of memory demands can be examined in so-called source memory tasks, in which items are presented in different study contexts. In a subsequent test phase, it has to be determined in which specific study context an item was presented. Since all items have been exposed during study to the same degree, relying on differences in item familiarity is not sufficient to solve these source memory tasks. Rather, the recollection of detailed contextual information is necessary for successful

The authors thank Martina Zink for help during data collection, as well as Jutta Kray and Hubert Zimmer, who provided helpful comments during manuscript preparation. Correspondence concerning this article should be addressed to D. Czernochowski, Cognitive Electrophysiology Laboratory, New York State Psychiatric Institute, Unit 6, 1051 Riverside Drive, New York, NY 10032 (e-mail: czernoc@pi.cpmc.columbia.edu). memory performance (see Yonelinas, 2002, for a detailed review of dual-process models).

Typically, the question regarding the source of the studied information either follows an old/new decision or replaces it (Source A vs. Source B vs. new). Unlike these source memory designs, in the exclusion paradigm (see Jacoby, 1991), the distinction between two sources of studied information is made by asking the participants to respond old to items belonging to only one of two study classes (i.e., targets), whereas items from the other study class (i.e., nontargets) are to be rejected along with new items. The mechanisms underlying these two types of memory, familiarity and recollection, and their development during childhood are the focus of this investigation.

Evidence for a dissociation between familiarity- and recollection-based recognition judgments comes from the examination of event-related potentials (ERPs). In general, correct responses to old items elicit more positivegoing waveforms than do correctly rejected new items (e.g., Friedman \& Johnson, 2000; Mecklinger, 2000). Typically, an early midfrontal old/new effect between 300 and $500 \mathrm{msec}$ can be dissociated from a later effect with a more parietal topography between 400 and $600 \mathrm{msec}$ (see Curran, 2000; Mecklinger, 2000). The parietal effect has been demonstrated to vary according to the amount of information retrieved from episodic memory (Wilding, 2000) and, hence, has been taken as a correlate of recollection (e.g., Wilding, 2000; Wilding \& Rugg, 1996). In contrast, the early midfrontal component has been associated with the global assessment of the similarity between study and test items that is accompanied by a subjective 
feeling of familiarity (e.g., Curran, 2000; Nessler, Mecklinger, \& Penney, 2001). Although the proposed functional significance of the early midfrontal component has not remained unchallenged (e.g., Yovel \& Paller, 2004), many studies have concluded that the early midfrontal component is independent of recollection, since it does not vary along with the amount of information retrieved in source tasks (Wilding, 2000). Recent studies suggest that in addition to the midfrontal effect between 300 and $500 \mathrm{msec}$, reflecting an amodal matching between study and test items, there is an even earlier onsetting frontopolar old/new effect that is modality specific (Curran \& Dien, 2003). The midfrontal old/new effect has furthermore been dissociated from ERP correlates of implicit memory processes (Nessler, Mecklinger, \& Penney, 2005; Rugg et al., 1998).

A third old/new effect that is often observed during recognition memory retrieval is pronounced in right frontal recordings. It is maximal at around the time the subjects are responding and is sustained in time for several hundred milliseconds. This old/new effect was first reported in a source memory study by Wilding and Rugg (1996), in which it was termed the right frontal old/new effect. Although it originally was considered to be an electrophysiological correlate of successful retrieval (e.g., Wilding \& Rugg, 1997), it has more recently also been found in situations in which memory retrieval was not successful (e.g., Trott, Friedman, Ritter, Fabiani, \& Snodgrass, 1999). Hence, the effect is less likely to reflect retrieval success per se but, rather, processes contingent upon retrieval, also termed postretrieval monitoring and evaluation (see Friedman \& Johnson, 2000).

Finally, in a number of recognition memory studies, a negative-going old/new effect, the late posterior negativity (LPN), has been reported over posterior regions with about the same temporal characteristics as the right frontal effect. On the basis of an extensive literature review, Johansson and Mecklinger (2003) suggested that the LPN is related to forming and maintaining a bound representation of the recognized item and task-relevant contextual attributes pertaining to the study episode.

\section{Control of Memory Retrieval}

A number of recent studies have stressed the important role of the prefrontal cortex (PFC) during explicit memory retrieval (e.g., Dobbins, Simons, \& Schacter, 2004; Ranganath, 2004; Wagner, 2002). It is generally assumed that control processes mediated by the PFC are responsible for guiding the efficient search for relevant item attributes or item-context attribute conjunctions (e.g., Dobbins, Foley, Schacter, \& Wagner, 2002). Whereas recollection, the retrieval of detailed information from a study episode mediated by the medial temporal lobes, can be considered to be a reflexive act triggered by a cue (Moscovitch, 1995), the PFC is necessary for setting up retrieval strategies and for adapting retrieval to the current task demands.

In Shimamura's (2002) dynamic filtering theory, the selection and maintenance of relevant information are the two most basic control operations mediated by the PFC. Recognition memory tasks can require various degrees of specificity with which information is searched for and retrieved from memory. The more specific the retrieval task, the more important are control processes for the successful retrieval of relevant information from episodic memory (Ranganath \& Paller, 1999, 2000). Ranganath (2004) recently proposed a model of hemispheric asymmetries in prefrontal control as a function of specificity of the retrieved information (see also Nolde, Johnson, \& Raye, 1998). According to this account, the left PFC is responsible for the selection of specific information from the study episode, whereas the right PFC is concerned with the retrieval of more undifferentiated memory contents, which requires a close monitoring of item familiarity. This view has been confirmed by a recent fMRI study by Dobbins et al. (2004), in which item memory and judgments of frequency were directly compared. For judgments of frequency, it was predicted that the recollection of an item's previous occurrence would be largely ineffective, since all the items had previously occurred; hence, the participants would need to monitor the level of each item's familiarity. In fact, this monitoring was reflected by right prefrontal activity that was not influenced by relative difficulty or the presence or absence of an identical retrieval cue (Dobbins et al., 2004).

Consistent with the notion that prefrontal control mechanisms are essential for the monitoring and verification of the products of memory retrieval, several clinical studies examining patients with frontal lobe pathology have reported specific problems during memory retrieval: Mayes and colleagues demonstrated that frontal lobe patients were able to perform at close to normal levels in an item recognition test but were at floor levels when source information was asked for (see Mayes, Holdstock, Isaac, Hunkin, \& Roberts, 2002; Schnider, 2003; Simons \& Spiers, 2003; Simons et al., 2002). In a similar vein, elderly people have been demonstrated to suffer from less effective control functioning and have larger problems with source memory requirements than would be expected from their item memory performance (e.g., Dywan, Segalowitz, \& Webster, 1998; Friedman, 2000; Trott et al., 1999). Since the frontal lobe structures not only are vulnerable to the effects of increasing age, but also have a very protracted development and continue to mature well into the adolescent years (e.g., Sowell, Delis, Stiles, \& Jernigan, 2001), it can be assumed that cognitive control processes continue to develop along with frontal lobe maturation.

\section{Development of Item and Source Memory in Childhood}

In contrast to the wealth of studies concerned with recognition memory retrieval in adults, the developmental trajectory of source, as opposed to item, memory is poorly understood so far. Although most researchers would agree that source memory develops later in life, since it is more closely connected to effective control functioning mediated by the prefrontal lobes, the exact time frame of this 
developmental process is unclear (see Cycowicz, 2000). In particular, the relative contribution of recollection and familiarity to item and source memory during childhood has not received much attention in the literature. Since this issue might have considerable practical implications for the reliance on children's memory retrieval-for instance, as witnesses in court-more conclusive evidence is necessary.

Behavioral studies indicate that item, as well as source, memory performance increases with age, with a steeper increase in performance for source, as compared with item, information (see Billingsley, Smith, \& McAndrews, 2002; Gathercole, 1998; Giles, Gopnik, \& Heyman, 2002). Unfortunately, quite often these findings have been based on very few items or have not been directly comparable, since many of the studies were based on recall tasks or face-to-face interviews, which have been shown to be susceptible to the format of the questions (e.g., Roebers \& Howie, 2003). One exception is a study by Cycowicz, Friedman, Duff, and Snodgrass (2001), who compared item and source recognition memory for 128 pictures with children 7-8 years of age and college students. The authors demonstrated that memory for the study color of the pictures was lower than item memory for these same pictures for both adults and children and that the increase in children's source memory performance was independent of their lower item memory performance. Rather, it was correlated with performance in neuropsychological tests of frontal lobe functions (i.e., word fluency and behavioral inhibition; Cycowicz et al., 2001).

Billingsley et al. (2002) examined the developmental trajectory of implicit and explicit memory with four age groups between 8 and 19 years. Although no age differences were found for perceptual and conceptual priming, explicit picture recognition memory was lower for 8- to 10 -year-old children, as compared with older participants. In addition to old/new decisions, the participants were required to give remember-know judgments (Tulving, 1985). Although the number of correct know responses was at floor level for all groups, the poorer performance by the youngest group was paralleled by a lower number of remember judgments, as compared with the older participants. When the false alarms connected with know responses were included in the analyses, it became apparent that the know category was used more often by the youngest children but that they were unable to differentiate between old and new items within this category (Billingsley et al., 2002).

This pattern of memory performance suggests that until about 10 years of age, young children predominantly use familiarity as a basis for their recognition judgments and only gradually increase the use of recollection. Alternatively, the low number of know responses could reflect an accurate subjective awareness - namely, that familiarity, indeed, is not the main process underlying children's responses. Item memory performance in that study was lower for the 8- to 10-year-olds, as compared with older participants, as was their percentage of remember judg- ments, suggesting that correct responses and the use of recollection are closely related. This response pattern could indicate the use of recollection-based old/new decisions with a very strict response criterion or, alternatively, a typically observed overconfidence in children's responses (Roebers, 2002; Roebers \& Howie, 2003; Ruffman, Rustin, Garnham, \& Parkin, 2001). It is conceivable that the young children mistook know judgments for mere guessing, since they may be lacking the fine-tuned cognitive control to incorporate those memory traces that do not rely on a definite recollective experience into their responses. Following this line of argumentation, the basis for the increase in recognition memory performance would be mainly the gradual increase of recollection, consistent with the observation that children and adolescents are very reluctant to give know responses on correct trials.

Taken together, these results indicate that until about 10 years of age, young children seem to lack the ability to reflect on the state of awareness associated with memory, which is closely related to the gradual development of metamemory (Gathercole, 1998).

Consistent with this view, young children below the age of 5 or 6 years are often unable to report the sources of their own knowledge, even immediately after they witness a particular event, which has been attributed to the slow emergence of a theory of mind between the ages of 3 and 6 years (O’Neill \& Gopnik, 1991). Giles et al. (2002) reported an inverse relationship between source-monitoring performance and suggestibility in 3- to 5-year-old children; that is, the better the children answer source-monitoring questions, the higher their ability to resist suggestions.

Beyond the evaluation of performance and subjective awareness accompanying recognition memory, ERPs can provide further insights into the brain mechanisms that mediate memory performance. A first ERP study with 9- to 10-year-old children, 12- to 13-year-old adolescents, and young adults suggests that children show evidence of recollection-based recognition judgments (Cycowicz, Friedman, \& Duff, 2003). In an exclusion version of the item and color memory task described above, performance improved with increasing age and was better for item memory, as compared with source memory, for all age groups. Cycowicz and colleagues found longer latencies and generally larger amplitudes in the ERPs of children and adolescents, as compared with adults. A centro-parietal old/new effect between 415 and $615 \mathrm{msec}$ was evident for all age groups in both item and source memory tasks. In the source task, an additional negativegoing late old/new effect was evident that had a parietal topography in adults and a more frontal topography in both children and adolescents. This topographical distribution was taken as evidence for the activation of qualitatively different neuronal networks - namely, a posterior network corresponding to the reactivation of visual information that was necessary for the retrieval of the items' colors for adults and more activation in children's PFC, due to the higher task demands or less finely tuned activation in children's brains. 
Although the authors did not focus on the relative contribution of familiarity and recollection, the parietal distribution of the positive-going old/new effect found with all age groups, as well as the time course between 415 and $615 \mathrm{msec}$, suggest that memory judgments were based mainly on recollection for all age groups. Unfortunately, ERP waveforms were depicted only for hits/targets and new items, and the pattern of results for nontargets was not reported in this study. Likewise, the performance in both item and source tasks was defined as hits minus false alarms to new items - that is, false alarms to nontarget items were not taken into account for either of the performance measures.

Taken together, the evidence regarding recognition memory in childhood and its neuronal correlates as measured by ERPs is far from conclusive. Although behavioral performance suggests that children rely predominantly on familiarity, the first ERP findings provide at least some evidence for a parietal old/new effect in 9- to 10-year-old children (Cycowicz et al., 2003), which in turn suggests that retrieval was mediated by recollection.

The aim of the present study was to further investigate item and source memory judgments by means of ERPs. As compared with previous ERP studies on item and source memory with children, our design contained three modifications. First, in order to evaluate the time course of memory development within childhood more precisely, two age groups of children (6-8 and $10-12$ years) were compared with young adults. Second, an exclusion task was chosen because, in addition to tapping source memory performance, it offers the possibility to assess agerelated changes in the processing of studied nontarget material. Since these items have been presented previously along with the targets, they should elicit the same amount of familiarity, which makes it crucial for successful performance to effectively inhibit a prepotent old response to these items. Finally, in contrast to many previous ERP studies on source memory, the two target contexts in the present study differed in more than one critical aspect. Since the term source refers to various features of the context in which the memory was acquired (Johnson, Hashtroudi, \& Lindsay, 1993), we tried to maximize the discriminability of the two sources, in order to avoid cases in which irrelevant context features could be recollected but not used to solve the task at hand. On the basis of the definition by Johnson et al., we consider multiple source features as more valid than just one feature.

\section{METHOD}

\section{Participants}

Three age groups participated in this study. Young children were 6-8 years old (mean age, 8 years; range, $6.3-8.11$ years; 9 of them male), older children were $10-12$ years old (mean age, 11.4 years; range, $10.2-12.8$ years; 10 of them male), and young adults (mainly college students) were 20-29 years old (mean age, 25.3 years; 9 of them male). Eighteen adults, 20 older children, and 16 younger children were included in the analyses. ${ }^{1}$ All the participants were righthanded and native German speakers. They reported being in good health and having normal or corrected-to-normal vision and hearing ability (as indicated by the parent, in the case of the children). The children were recruited from local schools. Both the children and their parents were thoroughly informed about the EEG procedure. The participants (or the children's parents) gave informed consent and received $€ 7.50 / \mathrm{h}$ in payment for their participation.

\section{Stimuli}

Three kinds of stimuli were used for the memory task: photos and spoken words were presented during study, to represent two very distinct study lists, whereas line drawings of the corresponding objects and of new items were used as test probes. This allowed us to use the modality of the previous presentation as source information. The test items ( pictures) consisted of a subset of the Snodgrass and Vanderwart (1980) black-and-white line drawings. ${ }^{2}$ The German names of those objects, spoken by a female voice (words), as well as colorful photos closely corresponding to the original black-andwhite line drawings ( photos), were used as study items.

The 198 items were divided into three sets, each containing the same number of items belonging to one of the following categories: animals, plants, body parts, furniture, food, musical instruments, vehicles, toys, and things around the house. The participants studied two of the sets (one as words, one as photos) and were tested on all three sets presented as line drawings. The assignment of stimulus set to experimental conditions (old-photo, old-word, and new) was counterbalanced across participants.

\section{Procedure}

The participants were seated in a comfortable chair throughout the experiment. The whole session lasted approximately $2 \mathrm{~h}$. The memory task was divided into three parts, with short breaks in between. Each part contained two study and two test blocks. During study, the participants were shown one block of 20 photos, and in the second block, they heard 20 spoken words. Each stimulus was presented for $1,000 \mathrm{msec}$ and was preceded by a fixation cross $(300 \mathrm{msec})$ and a black screen baseline period $(200 \mathrm{msec})$. After a 1,000-msec intertrial interval, the next study trial began. In both blocks, the task in the study block was to indicate whether the item was more typically found outdoors or indoors. In order to increase the likelihood that children would be able to discriminate the two sources, the screen background was illuminated in red during the photo presentation and was changed to blue during presentation of the words or vice versa. Thus, the participants could discriminate the two sources on the basis of the modality of the information (photo vs. spoken word), the background color (red vs. blue), and the order of presentation (first vs. second study block). The order of blocked presentation and the pairing of modality and color was counterbalanced across participants, as was the assignment of response buttons.

During test (exclusion task; see Jacoby, 1991), the participants were shown black-and-white line drawings (13 old target items, 13 old nontarget items, 9 new items) on a gray background. The participants were asked to indicate whether the item had been shown in a given target context before or not. Preceding this exclusion task, the participants performed an item recognition task with the remaining studied and new items, in which they indicated whether or not a test picture corresponded to an item in the study phase, irrespective of the modality in which it had been studied (old-new decisions). For the results of this inclusion task, see Czernochowski, Brinkmann, Mecklinger, and Johansson (2004). In the exclusion test phase, the participants pressed one of two response buttons with the index finger of each hand, one corresponding to targets and the other corresponding to both nontargets and new items. Each stimulus was preceded by a fixation cross $(300 \mathrm{msec})$ and a black screen baseline period $(200 \mathrm{msec})$ and was presented for $1,500 \mathrm{msec}$, after which the screen turned black for a maximum of 3,000 msec or until the response button was pressed. Following the response, visual feedback was given for $500 \mathrm{msec}$, to indicate whether the response was correct (happy face) or not (unhappy face), before the screen turned black for another $1,000 \mathrm{msec}$. Item numbers were chosen to ensure 
that the ratio between responding with right and left response buttons was similar in both tasks.

Target group was a between-subjects factor. For half of the participants in each age group, studied photos were defined as targets, whereas for the remaining participants studied words were defined as targets. To ensure that the participants would understand the procedure, a practice phase including both study and test blocks was run before the experiment started. In addition, the children were asked to explain the instructions to the experimenter in their own words before each block and were corrected if necessary.

\section{EEG Recordings}

Scalp voltages were recorded with $27 \mathrm{Ag} / \mathrm{AgCl}-$ electrodes (at the following sites, adapted from the standard 10-20 system: FP1, FP2, F7, F3, FZ, F4, F8, FC5, FC3, FCZ, FC4, FC6, T7, C3, CZ, C4, T8, CP3, CPZ, CP4, P7, P3, PZ, P4, P8, O1, and O2) at a sampling rate of $500 \mathrm{~Hz}$ with a right mastoid reference, and were rereferenced offline to linked mastoids. An electrooculogram (EOG) was recorded with additional electrodes located above and below the right eye and outside the outer canthi of the eyes. Electrode impedance was kept below $5 \mathrm{k} \Omega$. Both the EEG and the EOG were recorded continuously and were A-D converted with 16-bit resolution at a sampling rate of $500 \mathrm{~Hz}$.

Offline data processing involved low-pass filtering at $20 \mathrm{~Hz}$ and additional high-pass filtering at $0.5 \mathrm{~Hz}$. For each group, ERP averages were formed for correct responses to new items (correct rejections) and to correctly identified old target and nontarget items. The duration of the epochs was $1,700 \mathrm{msec}$, including a $200-\mathrm{msec}$ prestimulus interval that was used for baseline correction. Prior to averaging, each epoch was scanned for eye movement artifacts and for other artifacts. Because many of the children continued to move during the EEG recording, more trials had to be rejected for children than for adults. Mean trial numbers for hits were the following: young children, 14 (range, 9-22); older children, 15 (10-24); adults, $26(12-42)$. Mean trial numbers for correct rejections of nontargets were the following: young children, 15 (10-28); older children, 19 (12-30); adults, 29 (13-41). Mean trial numbers for correct rejections of new items were the following: young children, 15 (8-19); older children, 15 (7-21); adults, 21 (14-22). Even though average trial numbers were higher for adults than for both groups of children, the number of trials used for ERP averaging with the children was in the range usually used in studies examining individual differences in old/new effects (e.g., Mecklinger, von Cramon, \& Matthesvon Cramon, 1998; Smith \& Halgren, 1989). Ocular artifacts were corrected using a linear regression approach described by Gratton, Coles, and Donchin (1983).

\section{Analyses}

Memory accuracy was analyzed by calculating corrected recognition scores (Pr) separately for item memory and source memory. Recognition scores for item memory, $\operatorname{Pr}($ item), were calculated by subtracting the proportion of false alarms to new items from the proportion of target hits, whereas recognition scores for source memory, $\operatorname{Pr}$ (source), were formed by subtracting the proportion of false alarms to nontarget items from the proportion of target hits. Response bias was defined as $\mathrm{Br}[\mathrm{Br}=$ (false alarms to new items) $/(1-\operatorname{Pr})$; see Snodgrass \& Corwin, 1988]. In order to compare the age groups, between-groups ANOVAs were used and followed up with two orthogonal planned contrasts that reflect the main research questions (comparing children with adults, as well as young with older children, in order to detect age-related changes that occur within childhood). To compare reaction times for targets, nontargets, and new items, a two-factor mixed ANOVA with the within-subjects factor of response (old vs. new items) and the between-subjects factor of group was performed for both targets and nontargets.

For statistical analysis of the ERP data, repeated measures ANOVAs were conducted, and Greenhouse-Geisser corrections were made to correct for violations of the sphericity assumption. Corrected $p$ values are reported, along with uncorrected degrees of freedom. Nine electrodes were selected for these analyses: three midline electrodes (FZ, CZ, and PZ), along with bilateral frontal (F3 and F4), central (C3 and $\mathrm{C} 4)$, and parietal (P3 and $\mathrm{P} 4)$ recording sites. Initial ANOVAs were conducted with the factors of condition (target vs. nontarget vs. new), anterior-posterior (frontal vs. central vs. parietal), and laterality (left vs. midline vs. right) for each age group. Only effects that involve the factor of condition are reported and were followed up by subsidiary tests to assess condition effects at single levels of the anterior-posterior and laterality factors. Treatment magnitudes $\left(\varpi^{2}\right)$ were calculated to allow a comparison of effect sizes across electrode sites (Keppel \& Wickens, 2004).

Since response latencies varied between groups and visual inspection of the waveforms suggested pronounced group differences in the timing of the ERP effects under investigation, group-specific time windows were chosen for the statistical analyses of the old/new effects (see Trott et al., 1999). Mean amplitudes were evaluated in a time window from 800 to $1,000 \mathrm{msec}$ for the younger children, from 700 to $900 \mathrm{msec}$ for the older children, and from 450 to $650 \mathrm{msec}$ for the adults. These windows were selected because they cover the time intervals in which the old/new differences were largest for each of the groups. To be able to evaluate early and late frontal old/new effects for the adults, two additional time windows were chosen at 200-400 and 1,000-1,200 msec.

\section{RESULTS}

\section{Behavioral Results}

As is suggested by Table 1 , memory accuracy differed reliably between the age groups for $\operatorname{Pr}($ item $)[F(2,51)=$ $9.21, p<.01]$, as well as for $\operatorname{Pr}($ source $)[F(2,51)=19.72$, $p<.001]$. Planned contrasts between the groups on both measures revealed that the adults performed better than the children (both $p$ values $<.0001$ ). The groups of children did not differ in performance accuracy. However, for both measures, a reliable main effect of target group indicated that performance was better for the target photo than for the target word groups [Pr(item), $F(1,48)=7.78, p<$ $.01 ; \operatorname{Pr}$ (source), $F(1,48)=5.83, p<.05]$. For the younger and older children, the target subgroups differed reliably with respect to performance level on both performance measures [all $p \mathrm{~s}<.05$, with the exception of a marginally reliable difference for $\operatorname{Pr}$ (source) in older children,

Table 1

Overview of Performance Data

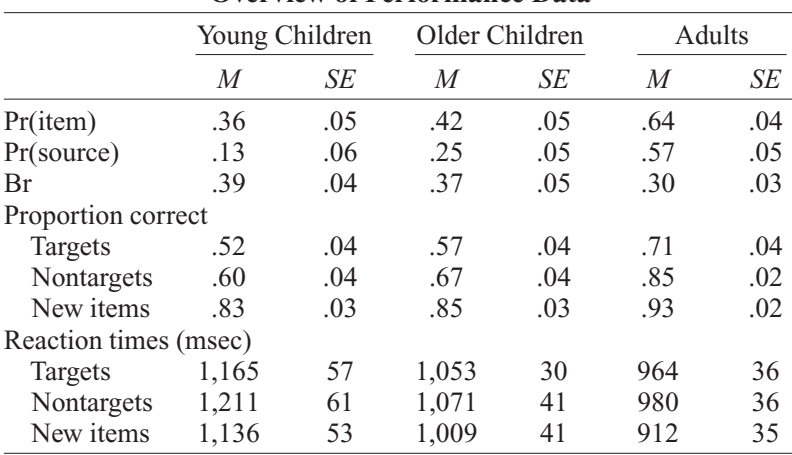

Note-Mean performance accuracy and response bias (Br) for the three age groups: Accuracy was calculated with respect to number of false alarms to new items $[\operatorname{Pr}($ item $)]$, as well as to nontargets $[\operatorname{Pr}($ source $)]$. 
Table 2

Item and Source Memory Performance for the Target Subgroups in Children and Adults

\begin{tabular}{|c|c|c|c|c|}
\hline \multirow[b]{2}{*}{ Target } & \multicolumn{2}{|c|}{ Children } & \multicolumn{2}{|c|}{ Adults } \\
\hline & $M$ & $S E$ & $M$ & $S E$ \\
\hline \multicolumn{5}{|l|}{ Photo } \\
\hline $\operatorname{Pr}($ item$)$ & .50 & .05 & .66 & .06 \\
\hline $\operatorname{Pr}$ (source) & .31 & .04 & .57 & .06 \\
\hline \multicolumn{5}{|l|}{ Word } \\
\hline $\operatorname{Pr}($ item$)$ & .36 & .05 & .62 & .06 \\
\hline $\operatorname{Pr}$ (source) & .19 & .05 & .58 & .07 \\
\hline
\end{tabular}

Note-Children, $n=31$; adults, $n=18$.

$p=.08]$. This effect of target group (photo vs. word) did not interact with age group, hence, further analyses are collapsed across the target groups to increase statistical power. With respect to response bias $(\mathrm{Br})$, the groups did not differ from each other $[F(2,51)<1]$.

Analyses of reaction times for targets and new items revealed a reliable main effect of group $[F(2,51)=8.12$, $p<.01]$, as well as of response type $[F(1,51)=8.19, p<$ $.01]$, but no interaction. Planned contrasts revealed that the children were slower than the adults $(p<.01)$ and the young children were slower than the older children $(p<$ .05 ). The same pattern of results was evident when reaction times were compared for nontargets and new items [main effect of group, $F(2,51)=8.21, p<.01$; children vs. adults, $p<.01$; younger vs. older children, $p<.05$; main effect of item type, $F(1,51)=20.79, p<.0001$, reflecting the fact that responses were slower for nontargets than for new items]. ${ }^{3}$

The analyses revealed an increase of performance accuracy as a function of age, no matter whether performance levels were corrected for false alarms to new items or to nontargets. Due to the nature of the exclusion task, however, it is not possible to distinguish between correct rejections of nontargets from misclassifications of nontargets as new items (i.e., misses). In fact, since both nontargets and new items received the same response, forgotten nontargets may have been misclassified as correctly rejected. Since children are more likely than adults to forget old nontargets, we may have overestimated their ability to correctly reject this specific type of studied material according to the exclusion instruction. Given the children's lower recognition performance in the inclusion task (see Czernochowski et al., 2004), we conducted an additional analysis in which we corrected the estimate for the number of nontarget false alarms for the likelihood of misses in the inclusion task. More specifically, we divided the proportion of false alarms to nontargets by the proportion of hits to the same item type (i.e., word or photo) in the inclusion recognition task. This provided us with an estimate of how many false positive responses occurred to items that were correctly classified as old in the inclusion task. As can be seen in Table 2, false positive responses to nontarget items in the youngest age group occurred in an estimated $67 \%$ of cases when they actually remembered that the item had been previously shown. Whereas this was true for the older children in an estimated $50 \%$ of the cases, the adults committed this particular error only in an estimated $16 \%$ of correct old classifications of nontarget items.

In order to compare whether the increase in source memory performance with increasing age is statistically independent from the performance increase in item mem-
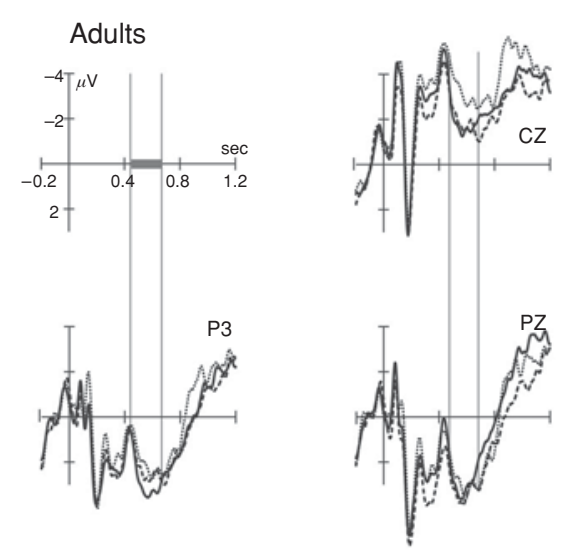

Older Children
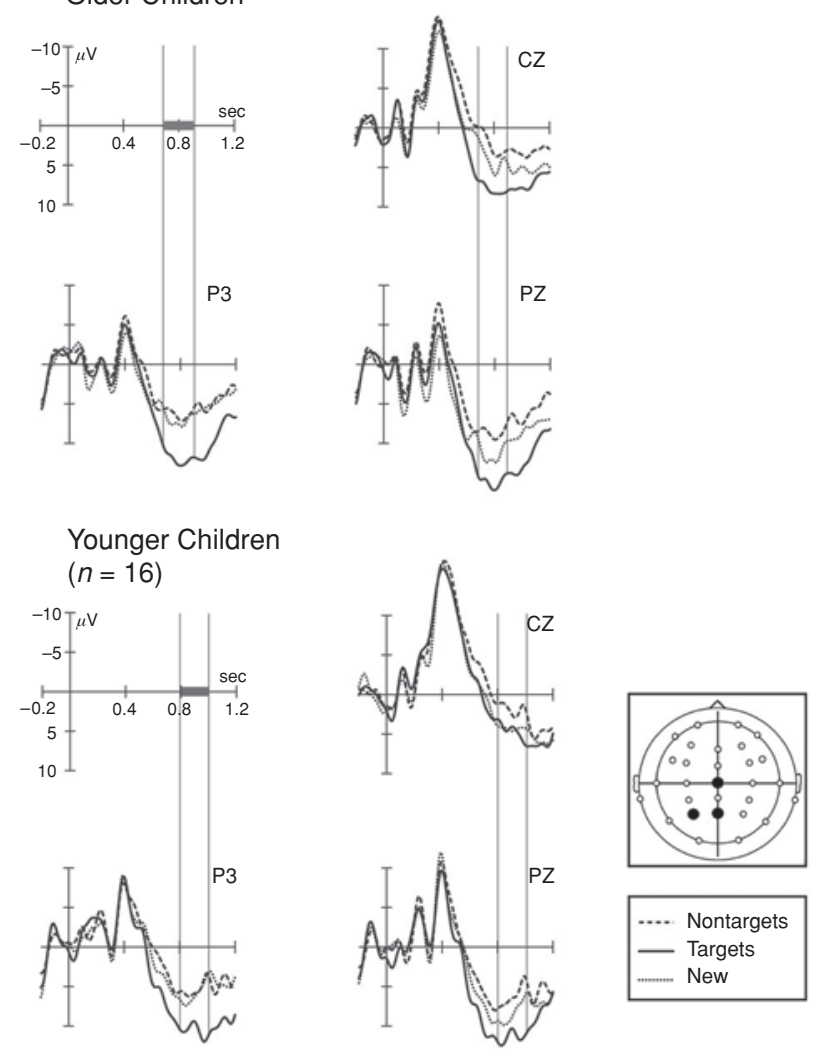

Figure 1. ERPs at selected electrode sites (CZ, P3, and PZ) for adults, 10- to 12-year-olds, and 6- to 8-year-olds. Targets are depicted as solid lines, nontargets as dashed lines, and correct rejections of new items as dotted lines. Time windows used for analyses were $450-650 \mathrm{msec}$ for adults, $700-900 \mathrm{msec}$ for older children, and 800-1,000 msec for younger children. Note the different scalings for adults and children, due to differences in overall amplitudes. 
Target Old/New Effects for the Three Age Groups

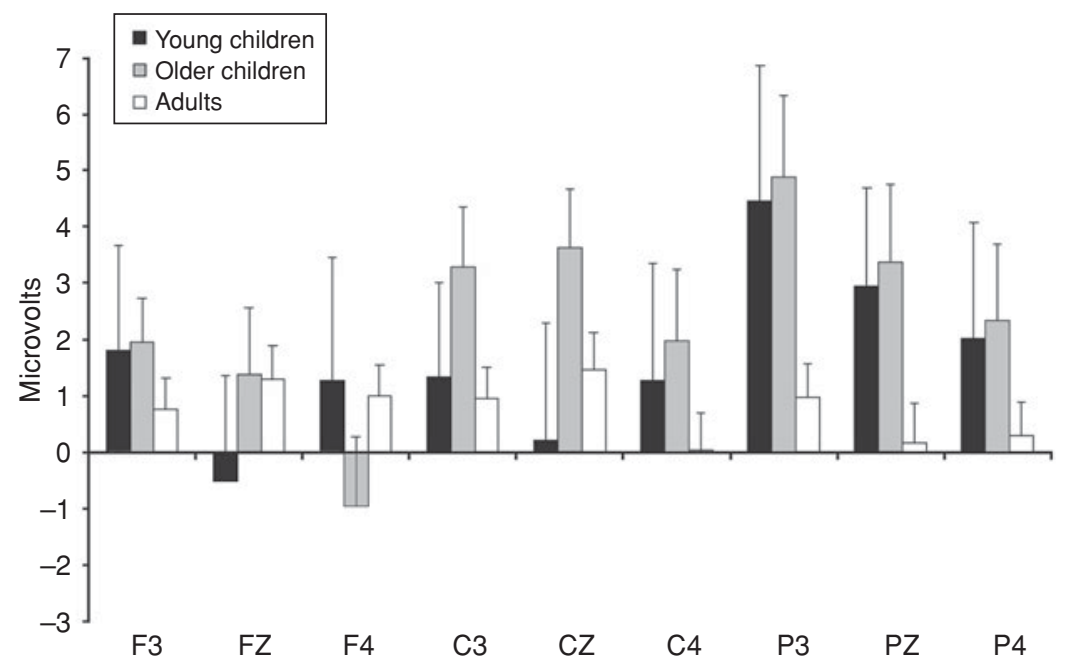

Figure 2. Mean amplitude differences (plus standard errors) between targets and new items at nine selected electrode sites for young children $(800-1,000$ msec, black bars), older children (700-900 msec, gray bars), and young adults $(450-650 \mathrm{msec}$, white bars). Note the age differences in amplitudes. Note that the old/new effect was widely distributed for the adults, whereas for the children it was largest at parietal electrodes.

ory, we used the performance in the inclusion task for the later target category as a covariate for the analysis of item and source memory performance. For item memory performance $\operatorname{Pr}($ item), an ANCOVA with the between factor of group revealed no reliable effect of group $[F(2,53)<$ 1]. The adjusted means for the performance in the item task after the influence of the covariate was partialled out were $.43, .46$, and .54 for the young children, the older children, and the adults, respectively.

The corresponding ANCOVA for the source memory performance revealed a reliable main effect of group $[F(2,53)=5.84, p<.01]$. The adjusted means for the performance in the source task after the influence of the covariate was partialled out were $.21, .28$, and .47 . Planned contrasts revealed a reliable difference between the adults and the children $(p<.01)$, but not between the two groups of children $(p>.28)$.

These results confirm the view that the increase in source memory is statistically independent of the increase in item memory performance. The adjusted means for the source memory performance further illustrate the agerelated changes in the ability to retrieve an item's source, given that the item itself is remembered.

\section{ERP Results}

Grand average ERPs for correct responses to targets, nontargets, and new items recorded at three selected electrode sites (CZ, P3, and PZ) for the three age groups are depicted in Figure 1. For illustration, the old/new effects (targets minus new) for all three age groups with the respective time intervals and all the electrodes that entered the ANOVAs are depicted in Figure 2.
Even though the waveforms for targets were generally more positive going than those for new items, the age groups differed in terms of latency, overall magnitude, and topography of the old/new effect: In the groups of children, the target old/new effects were most pronounced at parietal electrode sites (i.e., P3, PZ, and P4) between 700 and $800 \mathrm{msec}$ onward. Typical for children's ERPs are the overall larger amplitudes and a pronounced negative-going deflection with a maximum at midline frontal and central recordings (e.g., Cycowicz et al., 2003; Marshall, Drummey, Fox, \& Newcombe, 2002) that was evident for all conditions between 400 and $600 \mathrm{msec}$ (see electrode CZ in Figure 1). The overall larger amplitudes for both groups of children are also illustrated in the amplitudes of the difference waves (targets minus correct rejections of new items) displayed in Figure 2. Whereas in the adults the amount of recollected information was correlated with the amplitude of the parietal old/new effect (Wilding, 2000), this was not necessarily true for the comparison between age groups, since the children's ERPs had generally larger amplitudes because of maturational changes. Thus, changes in the magnitude of the old/new effect across age groups cannot be ascribed solely to the amount of information retrieved from memory.

For the adults, the difference between targets and new items showed a more widespread distribution, with a maximum at the central electrodes. Additional old/new differences were evident at the (left) frontal and central electrode sites (i.e., F3, FZ, C3, and CZ) in an earlier time window (200-400 $\mathrm{msec})$, as well as at the right frontal electrode sites (i.e., F4) in a later (1,000-1,200 msec) time window. The early left frontal effect reflects the fact 
Table 3

Summary of Statistical Results for the Initial ANOVA Performed for Each Group

\begin{tabular}{|c|c|c|c|c|c|c|c|c|c|}
\hline \multirow[b]{2}{*}{ Group } & \multirow{2}{*}{$\begin{array}{l}\text { Time Window } \\
(\mathrm{msec})\end{array}$} & \multicolumn{2}{|c|}{ Condition (C) } & \multicolumn{2}{|c|}{$\begin{array}{c}\mathrm{C} \times \text { Laterality } \\
(\mathrm{L})\end{array}$} & \multicolumn{2}{|c|}{$\begin{array}{l}\mathrm{C} \times \text { Anterior- } \\
\text { Posterior }(\mathrm{AP})\end{array}$} & \multicolumn{2}{|c|}{$\mathrm{C} \times \mathrm{L} \times \mathrm{AP}$} \\
\hline & & $d f$ & $F$ & $d f$ & $F$ & $d f$ & $F$ & $d f$ & $F$ \\
\hline Adults & $450-650$ & 2,34 & $3.28^{\dagger}$ & 4,68 & $2.84^{*}$ & 4,68 & n.s. & 8,136 & n.s. \\
\hline Older children & $700-900$ & 2,38 & $8.41^{* *}$ & 4,76 & $3.03^{\dagger}$ & 4,76 & $2.90^{\dagger}$ & 8,152 & n.s. \\
\hline $\begin{array}{l}\text { Younger children } \\
\quad(n=16)\end{array}$ & $800-1,000$ & 2,30 & n.s. & 4,60 & n.s. & 4,60 & n.s. & 8,120 & n.s. \\
\hline $\begin{array}{l}\text { Younger children } \\
\quad(n=11)\end{array}$ & $800-1,000$ & 2,20 & $5.80^{*}$ & 4,40 & n.s. & 4,40 & n.s. & 8,80 & n.s. \\
\hline
\end{tabular}

that both types of old items elicited more positive-going ERPs than did new items, whereas the late right frontal effect took the form of targets eliciting more positive-going waveforms than did new items and nontargets. A summary of the statistical results of the initial ANOVAs for the three age groups can be found in Table 3 .

Parietal old/new effects in the three age groups. For the group of adults, a marginally significant main effect of condition and a reliable interaction between condition and laterality were found for the $450-650 \mathrm{msec}$ time window. Analyses at the single electrodes revealed reliable differences between targets and new items at frontal electrodes, as well as at $\mathrm{C} 3, \mathrm{CZ}$, and $\mathrm{P} 4$. The treatment magnitude was largest at $\mathrm{FZ}\left(\varpi^{2}=.34\right)$. Nontargets differed reliably from new items at F3, FZ, and F4 and marginally so at P3 (see Table 3). Treatment magnitude for this nontarget old/new effect was largest at FZ $\left(\varpi^{2}=.32\right)$. The two types of old items differed reliably only at PZ, with targets being more negative going at this electrode site than were nontargets.

The group of older children showed a main effect of condition and marginally significant interactions between condition and laterality and between condition and anteriorposterior between 700 and $900 \mathrm{msec}$. Subsidiary analyses revealed reliable old/new effects for targets at F3, C3, $\mathrm{CZ}, \mathrm{P} 3$, and PZ (see Table 4). Treatment magnitudes were largest at $\mathrm{CZ}\left(\varpi^{2}=.34\right)$ and $\mathrm{P} 3\left(\bar{\varpi}^{2}=.34\right)$. Nontargets differed reliably from new items at F4 $\left(\bar{\omega}^{2}=.22\right)$ and as a trend at $\mathrm{C} 4\left(\bar{\varpi}^{2}=.10\right)$ and $\mathrm{PZ}\left(\varpi^{2}=.08\right)$. Targets and nontargets differed reliably at all electrodes except F4; at
FZ, this difference was only marginally significant (see Table 4). As can be seen in Figure 2, the initial interactions reflect the fact that the old/new effect tended to show a left-sided asymmetry and to be larger over parietal than over more anterior electrodes.

In the group of younger children, neither the main effect nor any interaction involving the factor of condition reached significance in the initial ANOVA ( $p$ s $>$ .14). Since visual inspection of the waveforms suggests a rather large parietal effect (see Figures 1 and 2), subsidiary analyses at single electrodes were performed and revealed a trend for an old/new effect at P3 between 800 and 1,000 msec (see Table 4; $p=.08, \varpi^{2}=.13$ ). Target hits and nontarget correct rejections differed reliably at P3 $(p<.01)$ and PZ $(p<.05)$, with targets being more positive than nontargets.

It is conceivable that the absence of reliable old/new effects for the younger children resulted from a combination of lower task performance and a larger number of guess responses to old and new items. To examine this issue, we performed an additional analysis, in which the 5 children with the lowest source memory performance were excluded. The ANOVA for the resulting subgroup of better performing young children $(n=11)$ revealed a main effect of condition $[F(2,20)=5.8, p<.05]$. As can be seen in Figure 3, a reliable old/new effect was seen at $\mathrm{PZ}$ and marginally reliable old/new effects were obtained at C3, C4, P3, and P4. Both types of old items differed reliably at C4, P3, PZ, and P4 (see Table 3). Treatment

Table 4 Summary of Statistical Results for the Subsidiary ANOVAs Performed for Each Group for Nine Selected Electrode Sites

\begin{tabular}{|c|c|c|c|c|c|c|c|c|c|c|c|c|}
\hline \multirow[b]{2}{*}{ Group } & \multirow{2}{*}{$F(d f)$} & \multirow{2}{*}{$\begin{array}{c}\text { Time Window } \\
(\mathrm{msec})\end{array}$} & \multirow[b]{2}{*}{ Contrast } & \multicolumn{9}{|c|}{ Electrode Site } \\
\hline & & & & F3 & FZ & F4 & $\mathrm{C} 3$ & $\mathrm{CZ}$ & $\mathrm{C} 4$ & $\mathrm{P} 3$ & $\mathrm{PZ}$ & $\mathrm{P} 4$ \\
\hline Adults & $F(1,17)$ & $450-650$ & $\begin{array}{l}\text { Hit vs. new } \\
\text { Hit vs. nontarget }\end{array}$ & $5.65^{*}$ & $10.78^{* *}$ & $4.80^{*}$ & $5.79^{*}$ & $5.08^{*}$ & & & $8.21^{*}$ & $6.30^{*}$ \\
\hline & & & New vs. nontarget & $2.87^{\dagger}$ & $10.02^{* *}$ & $4.97^{*}$ & & & & $2.87^{\dagger}$ & & \\
\hline Older children & $F(1,19)$ & $700-900$ & $\begin{array}{l}\text { Hit vs. new } \\
\text { Hit vs. nontarget } \\
\text { New vs. nontarget }\end{array}$ & $\begin{array}{l}6.74^{*} \\
4.63^{*}\end{array}$ & $3.65^{\dagger}$ & $6.97^{*}$ & $\begin{array}{r}9.52^{* *} \\
12.06^{* *}\end{array}$ & $\begin{array}{l}11.76^{* *} \\
13.92^{* *}\end{array}$ & $\begin{array}{l}7.89^{*} \\
3.22^{\dagger}\end{array}$ & $\begin{array}{l}11.28^{* *} \\
12.00^{* *}\end{array}$ & $\begin{array}{c}6.03^{*} \\
14.90^{* *} \\
2.85^{\dagger}\end{array}$ & $\begin{array}{r}3.07 \dagger \\
8.34^{* *}\end{array}$ \\
\hline Young children & $F(1,15)$ & $800-1,000$ & $\begin{array}{l}\text { Hit vs. new } \\
\text { Hit vs. nontarget } \\
\text { New vs. nontarget }\end{array}$ & $3.05^{\dagger}$ & & & & & $5.03^{*}$ & $\begin{array}{l}3.46^{\dagger} \\
7.79^{*}\end{array}$ & $8.30^{*}$ & \\
\hline Young children & $F(1,10)$ & $800-1,000$ & $\begin{array}{l}\text { Hit vs. new } \\
\text { Hit vs. nontarget } \\
\text { New vs. nontarget }\end{array}$ & & & & $4.23^{\dagger}$ & & $\begin{array}{c}4.26^{\dagger} \\
13.39^{* *}\end{array}$ & $\begin{array}{l}4.36^{\dagger} \\
9.86^{*}\end{array}$ & $\begin{array}{r}6.16^{*} \\
21.01^{* *}\end{array}$ & $\begin{array}{l}4.84^{\dagger} \\
9.88^{*}\end{array}$ \\
\hline
\end{tabular}

${ }^{*} p<.05 . \quad{ }^{* *} p<.01 . \quad{ }^{\dagger} p<.10$. 
Younger Children

$(n=11)$
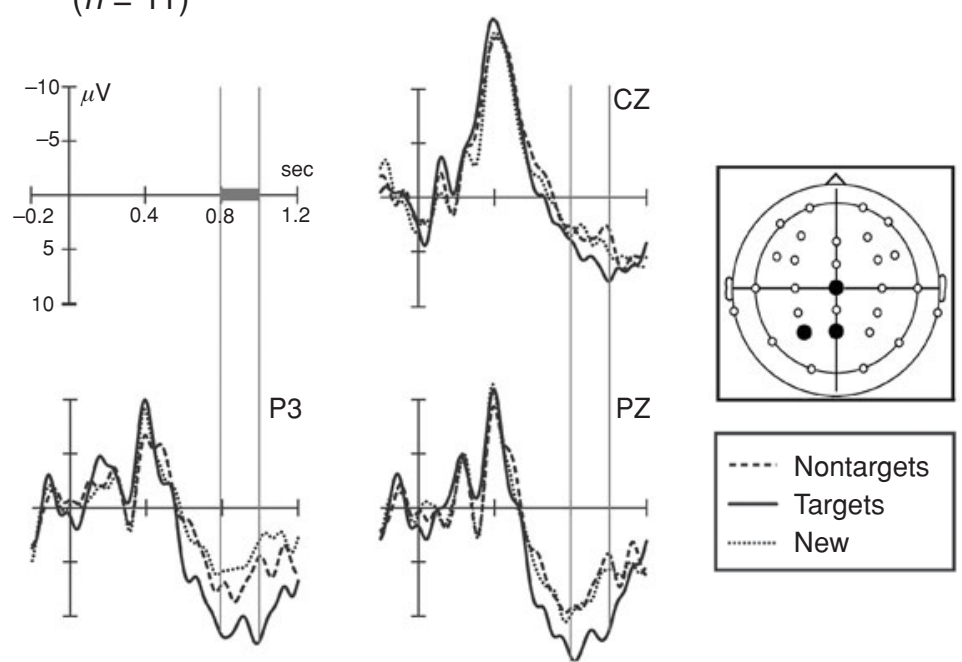

Figure 3. ERPs at selected electrode sites (CZ, P3, and PZ) for a subgroup of the younger children $(n=11)$ after excluding the 5 younger children with the lowest performance. The time window used for analyses was $800-1,000 \mathrm{msec}$. Targets are depicted as solid lines, nontargets as dashed lines, and correct rejections of new items as dotted lines.

magnitudes were largest at $\mathrm{PZ}\left(\varpi^{2}=.30\right)$ and were still considerably large at P4 $\left(\varpi^{2}=.24\right), \mathrm{P} 3\left(\varpi^{2}=.22\right)$, and $\mathrm{C} 3$ and $\mathrm{C} 4\left(\varpi^{2}=.21\right)$.

To summarize, the adults and older children showed reliable parietal old/new effects, although delayed for about 300-400 msec in the children group. For the young children, these effects reached significance only when 5 subjects with a particularly low performance level were excluded. For both groups of children, the effects were largest at left parietal electrodes.
Frontal old/new effects for adults. On the basis of a visual inspection of the data, two additional time windows were specified for the adults. As is suggested by Figure 4, in the early (200-400 msec) time window, reliable interactions were found for condition and laterality, condition and anterior-posterior, and condition, anterior-posterior, and laterality (see Table 5).

As is apparent in Table 6, analyses for single electrodes revealed reliable differences between targets and new items at F3, FZ, F4, C3, and C4. Treatment magnitudes
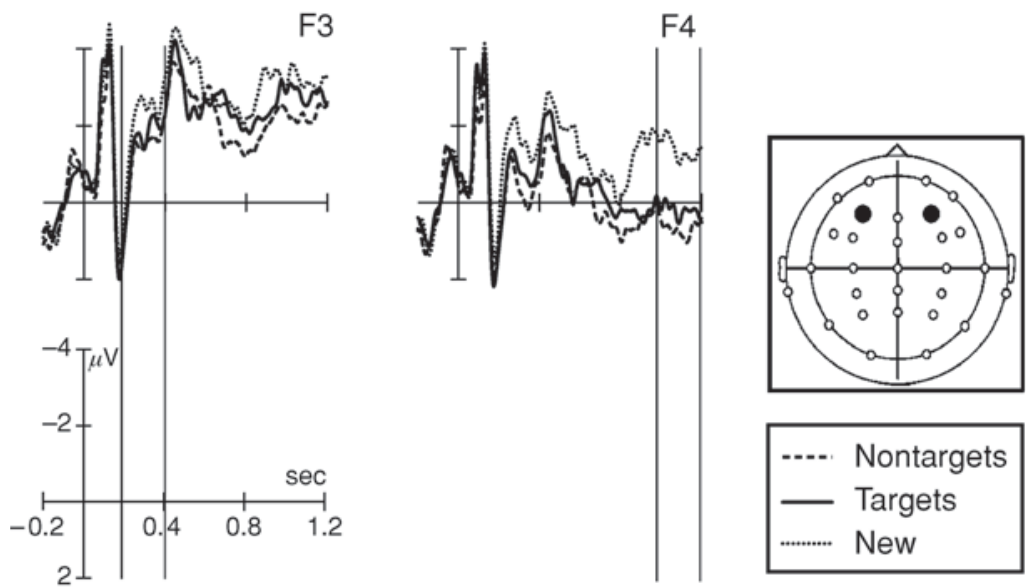

Figure 4. ERPs at selected frontal electrode sites (F3 and F4) for adults. Targets are depicted as solid lines, nontargets as dashed lines, and correct rejections of new items as dotted lines. Time windows used for analyses are indicated by the gray lines (200-400 msec at F3 and 1,000-1,200 msec at F4). 
Table 5

Summary of the Statistical Results for the Initial ANOVA for the Adults at Frontal Electrode Sites

\begin{tabular}{|c|c|c|c|c|c|c|c|c|}
\hline \multirow{2}{*}{$\begin{array}{l}\text { Time Window } \\
(\mathrm{msec})\end{array}$} & \multicolumn{2}{|c|}{$\begin{array}{l}\text { Condition } \\
\text { (C) }\end{array}$} & \multicolumn{2}{|c|}{$\begin{array}{c}\mathrm{C} \times \\
\text { Laterality } \\
\quad(\mathrm{L})\end{array}$} & \multicolumn{2}{|c|}{$\begin{array}{c}\mathrm{C} \times \\
\text { Anterior- } \\
\text { Posterior } \\
(\mathrm{AP})\end{array}$} & \multicolumn{2}{|c|}{$\mathrm{C} \times \mathrm{L} \times \mathrm{AP}$} \\
\hline & $d f$ & $F$ & $d f$ & $F$ & $d f$ & $F$ & $d f$ & $F$ \\
\hline $200-400$ & 2,34 & n.s. & 4,68 & $3.81^{*}$ & 4,68 & $3.31^{*}$ & 8,136 & $2.78^{*}$ \\
\hline $1,000-1,200$ & 2,34 & n.s. & 4,68 & n.s. & 4,68 & n.s. & 8,136 & $2.25^{* *}$ \\
\hline
\end{tabular}

for the target old/new effect were largest at $\mathrm{C} 3\left(\varpi^{2}=.24\right)$ and F3 $\left(\varpi^{2}=.20\right)$. Nontargets differed reliably from new items at $\mathrm{F} 3, \mathrm{C} 3$, and $\mathrm{CZ}$, whereas no differences between both types of old items were found. Treatment magnitudes for the nontarget old/new effect were largest at FZ $\left(\varpi^{2}=\right.$ $.33), \mathrm{F} 3\left(\varpi^{2}=.28\right)$, and $\mathrm{CZ}\left(\varpi^{2}=.26\right)$.

In the late time window $(1,000-1,200 \mathrm{msec})$, the threeway interaction was marginally significant $[F(8,136)=$ $2.25, p=.07]$. More specific analyses at single electrodes were conducted and revealed a reliable old/new effect at $\mathrm{FZ}$ and F4 only for old target items. Treatment magnitudes were largest at F4 $\left(\varpi^{2}=.21\right)$ and were slightly smaller at $\mathrm{FZ}\left(\varpi^{2}=.15\right)$.

Topography of the old/new effects for the three age groups. The topography of the target old/new differences for the three groups can be seen in Figure 5. For 6- to 8-year-olds, the old/new effect had a very posterior distribution with a left parieto-occipital focus. The group of 10- to 12-year-olds demonstrated a left-lateralized old/new effect over parietal electrodes. For the adults, the old/new effect had a central to right frontal distribution, presumably reflecting the combination of a centrally focused old/new effect and the early onset of the late right frontal effect within the $450-650 \mathrm{msec}$ time window. In addition, only the adult group showed reliable old/new effects for targets and nontargets in the $200-400 \mathrm{msec}$ and the 450-600 msec time windows at midfrontal recording sites. Consistent with the view that midfrontal old/new effects in this time interval reflect the contribution of familiarity to recognition judgments, we take the former result to suggest that both types of old items elicited a familiarity signal for the adults only. An additional late
$(1,000-1,200 \mathrm{msec})$ right frontal effect was observed for targets in the adult group only.

Target and nontarget old/new effects. In order to examine age-related changes in the processing of nontarget material, in a next step, old/new differences were compared according to target status. Whereas both groups of children failed to show old/new effects for nontargets, these items elicited an effect comparable to the target old/ new effect in the adult group (see Figure 6). Since the target and nontarget trials were collapsed across categories (i.e., photos and words), it is conceivable that the absence of nontarget old/new effects in children is due to the fact that nontarget old/new effects were elicited only by one type of nontarget (photo or word), but not by the other. To examine this, we computed the nontarget old/new effect separately for both target categories (photos vs. words).

As is apparent from Figure 7, the old/new effect in adults seems to be confined to the actual target items in the target photo group $(n=9)$, whereas similar old/new effects for targets and nontargets are evident in the target word group $(n=9)$. This observation could be confirmed by statistical analyses: For the adults in the target photo group, an ANOVA with the factors of condition, laterality, and anterior-posterior revealed a three-way interaction $[F(8,64)=2,46, p=.05]$. Treatment magnitudes for the target photo old/new effect in this subgroup were largest at FZ $\left(\varpi^{2}=.20\right)$. Nontarget items did not elicit a reliable old/new effect at any electrode and differed reliably from target hits at PZ $[F(1,8)=6,47, p<.05]$. Conversely, the adult target word group showed a quite different pattern of old/new effects. The three-way ANOVA yielded a reliable main effect of condition $[F(2,16)=4,71, p=.05]$.

Table 6

Summary of Statistical Results for the Subsidiary ANOVAs Performed for the Adults for Nine Selected Electrode Sites

\begin{tabular}{|c|c|c|c|c|c|c|c|c|c|c|c|c|}
\hline \multirow[b]{2}{*}{ Group } & \multirow[b]{2}{*}{$F(\mathrm{df})$} & \multirow{2}{*}{$\begin{array}{c}\text { Time window } \\
(\mathrm{msec})\end{array}$} & \multirow[b]{2}{*}{ Contrast } & \multicolumn{9}{|c|}{ Electrode Site } \\
\hline & & & & F3 & FZ & $\mathrm{F} 4$ & C3 & $\mathrm{CZ}$ & $\mathrm{C} 4$ & P3 & $\mathrm{PZ}$ & $\mathrm{P} 4$ \\
\hline \multirow[t]{6}{*}{ Adults } & $F(1,17)$ & $200-400$ & Hit vs. new & $5.75^{*}$ & $4.68^{*}$ & $3.86^{\dagger}$ & $6.99^{*}$ & $5.33^{*}$ & & & & \\
\hline & & & Hit vs. nontarget & & & & & & & & & \\
\hline & & & New vs. nontarget & $8.40^{*}$ & & & $10.22^{* *}$ & $7.64^{*}$ & & & & \\
\hline & & $1,000-1,200$ & Hit vs. new & & $4.38^{\dagger}$ & $5.94^{*}$ & & & & & & \\
\hline & & & Hit vs. nontarget & & & & & & & & & \\
\hline & & & New vs. nontarget & & & & & & & & & \\
\hline
\end{tabular}



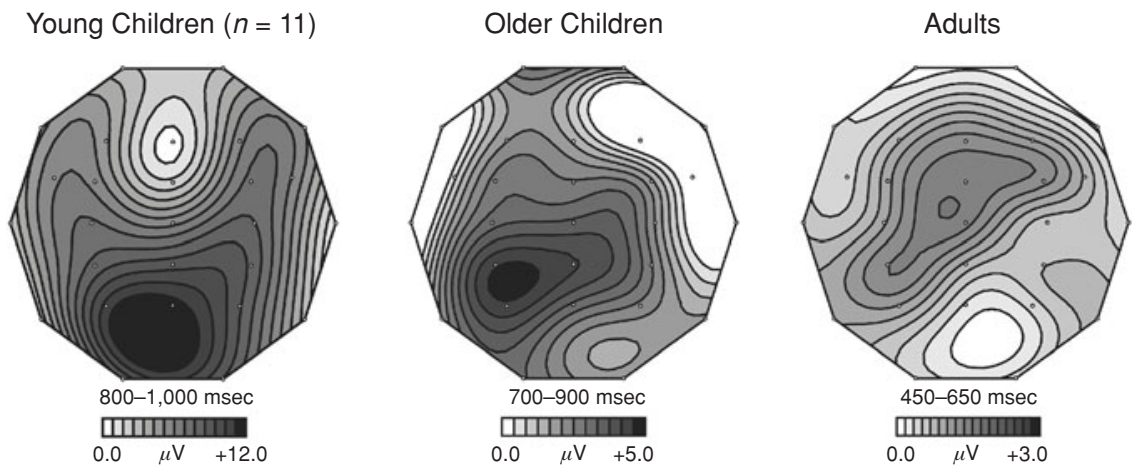

Figure 5. Topographies of the target old/new effect for the subset of young children (left), for older children (middle), and for adults (right) during the time windows that were used for analyses of the parietal old/new effect ( $800-1,000 \mathrm{msec}$ for young children, $700-900 \mathrm{msec}$ for older children, and $450-650$ msec for adults). Note the different scaling to illustrate the topographical distribution.

Both types of old items elicited reliable old/new effects at F3, FZ, and CZ $[F(1,8)>5, p<.05]$. Treatment magnitudes were even higher for nontarget photos than for target words (e.g., at CZ, the effect size for targets was $\bar{w}^{2}=$ .32 , and for nontargets it was $\varpi^{2}=.48$; see Figure 7).

In order to increase the power for the comparison of target subgroups, we collapsed across both child age groups for the target category analysis $(n=11$ better performing younger and 20 older children). For children, no old/new effects were observed for nontargets (see Figure 7, right). The three-way ANOVA revealed a main effect of condition $[F(2,60)=13.03, p<.0001]$ and an interaction of condition and laterality $[F(4,120)=4, p<.05]$. Reliable target old/new effects were found at F3, C3, CZ, C4, P3, $\mathrm{PZ}$, and P4 (all $p$ values $<.01$ ), with no reliable old/new effects for nontargets. For the children in the target photo group $(n=17)$, a reliable main effect of condition was found $[F(2,32)=4.66, p<.05]$. Target old/new effects were significant at $\mathrm{F} 3$ and were marginally significant at $\mathrm{C} 3$ and $\mathrm{P} 3(p<.07)$. There were no reliable nontarget old/new effects. For the children in the target word group $(n=14)$, a reliable main effect of condition $[F(2,26)=$ $10.59, p<.01]$ and an interaction of condition and laterality $[F(4,52)=5.75, p<.01]$ were obtained. Reliable target old/new effects were found at all central and parietal electrode sites (all $p \mathrm{~s}<.05$ ). As is evident in Figure 7, again, no reliable nontarget old/new effects were seen.

As can be seen in Table 7, the effects of the target category on the performance level differed as a function of age group. Whereas the adult target subgroups did not differ in performance levels (both $F_{\mathrm{s}}<1$ ), better picture than word processing was evident for the collapsed group of children $(n=31)$ : Those in the target photo subgroup $(n=17)$ performed better than those in the target word subgroup $[n=$ 14 ; reliably for item memory, $F(1,29)=4.62, p<.05$; as a trend for source memory, $F(1,29)=3.27, p=.08]$.

Taken together, the analyses of target and nontarget old/ new effects performed separately for each target group confirmed that nontarget old/new effects were obtained for adults when photos served as the nontargets, whereas nontarget old/new effects were absent for children regard- less of whether words or photos served as the nontargets. For the adults, performance did not differ as a function of target subgroup, whereas the children performed better when photos were the targets.

Analysis of ERP trials corresponding to misses and nontarget false alarms for children. In an additional step of analysis, we examined whether the parietal old/new effect for children could indeed be taken as a correlate of recollection or whether alternative explanations could account for this effect. In fact, the finding of a similar parietal old/new effect for children and adults, for which the parietal old/new effect is associated with recollection-based judgments, does not imply that the same processes are reflected in the children's effect. Two alternative accounts for the children's parietal old/new effect were tested. First, we examined whether it reflects a form of implicit memory that may have contributed to the children's old/new effects. A variety of ERP studies have

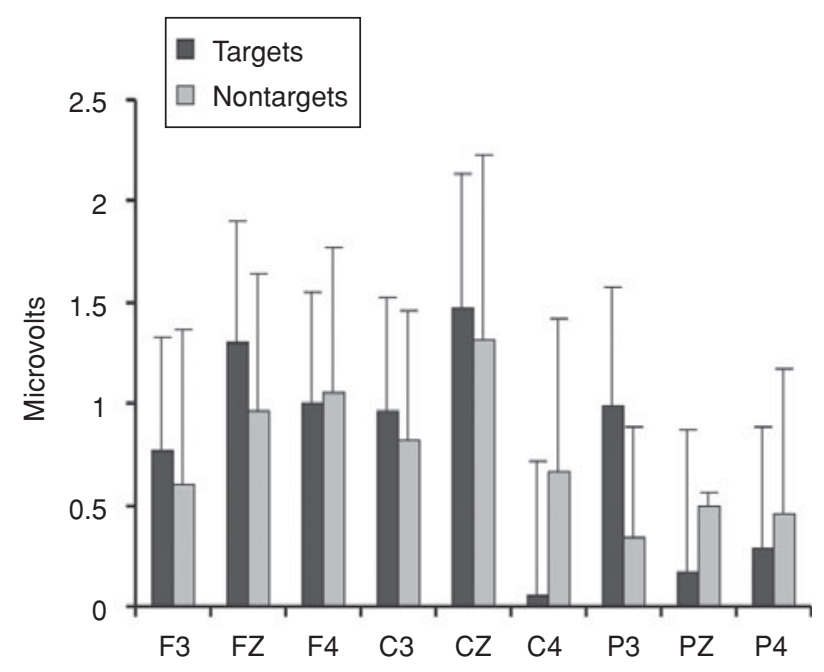

Figure 6. Target and nontarget old/new effects (plus standard errors) for the adults. Depicted are the means of the respective difference waves of targets and nontargets minus new items at selected electrode sites between 450 and 650 msec. 


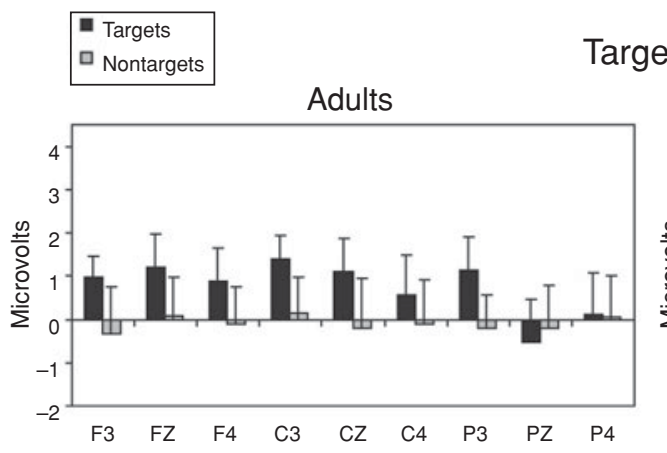

Target Photo

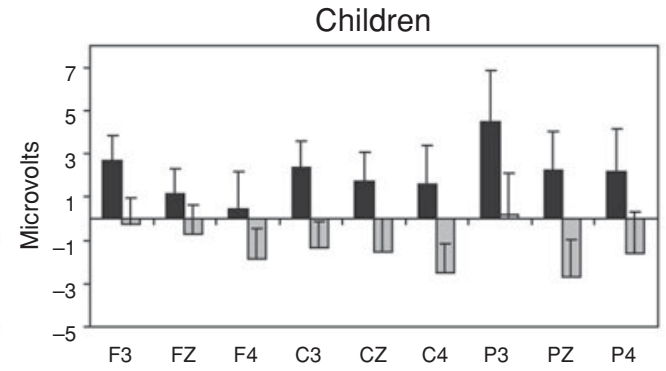

Target Word
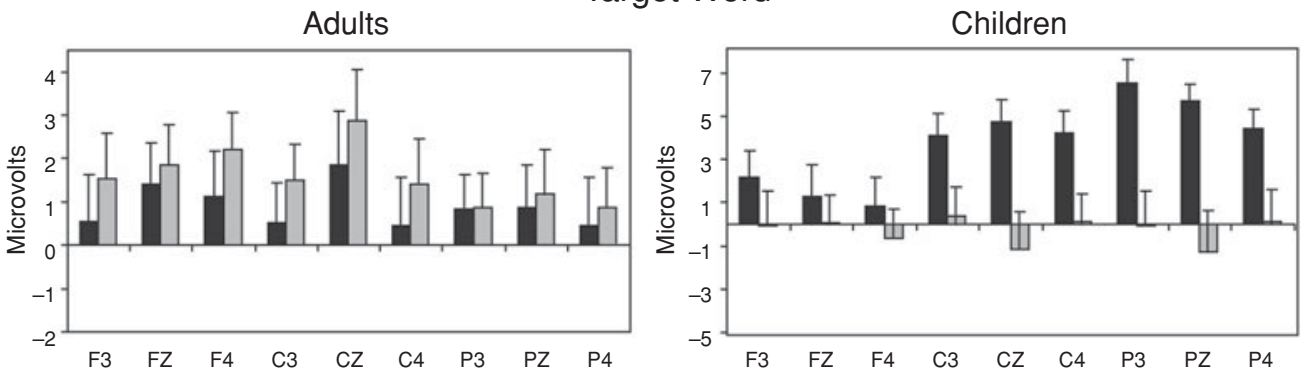

Figure 7. Target and nontarget old/new effects (plus standard errors) for adults (left) and children (right). The target photo and target word subgroups are depicted in the upper and lower rows, respectively.

revealed ERP correlates of implicit memory that resemble the parietal old/new effect taken as correlate of recollection (Nessler et al., 2005; Rugg et al., 1998). Given this and the lower explicit memory performance by children, it is conceivable that the parietal old/new effect for children is at least partly a reflection of implicit memory. If this is indeed the case, it should be present for all old items, irrespective of the subjective awareness of the previous occurrence - that is, for hits and for misses (Rugg et al., 1998). However, if miss responses do not elicit a comparable old/new effect, this alternative explanation can be ruled out, indicating that the parietal old/new effect is a consequence of the explicit memory trace, which is present for the target hits, but not for the misses.

We tested this hypothesis with a subset of 24 children (across both age groups) for whom reliable ERPs to misses could be formed. ERPs to correct responses were compared with the erroneous responses for the same subset of children in the time window from 800 to $1,000 \mathrm{msec}$.

For this analysis, the factor of condition in the initial ANOVA involved targets, nontargets, new items, and misses. For this subset of children, a reliable main effect of condition $[F(3,69)=3.28, p<.05]$ and an interaction of condition and laterality $[F(6,138)=4.70, p<.01]$ were found. More specific analyses at single electrodes were conducted and revealed a reliable old/new effect at C3, P3, and PZ only for old target items. Importantly, no reliable old/new effects were obtained for misses. Furthermore, targets and misses differed reliably at C3, CZ, P3, $\mathrm{PZ}$, and $\mathrm{P} 4$ (all $p \mathrm{~s}<.05)$. These results argue against an implicit memory account for the parietal old/new effects with children.

Second, another objection against the recollection account of the parietal old/new effect with children could be that it is related to the perceived target status of an item (Dywan, Segalowitz, \& Arsenault, 2002; Dywan, Segalowitz, Webster, Hendry, \& Harding, 2001). If the target status itself leads to a larger parietal late component, the parietal old/new effect should be found for all trials that received a target response - that is, hits and false alarms. A selective parietal old/new effect for targets, however, would favor the recollection account.

We tested this hypothesis with a subset of 16 children (both age groups) for whom reliable ERPs for false alarms to nontarget items could be formed. For this analysis, the factor of condition in the initial ANOVA involved targets, nontargets, new items, and false alarms to nontargets. In this subgroup of children, a reliable main effect of condition $[F(3,45)=4.36, p<.05]$ and an interaction of condition and laterality $[F(6,90)=2.90, p<.05]$, as well

Table 7

Estimates of the Proportion of False Alarms to Nontarget Items Corrected for Nontarget Item Forgetting

\begin{tabular}{|c|c|c|c|c|c|c|}
\hline \multirow[b]{2}{*}{ Target } & \multicolumn{2}{|c|}{ Young Children } & \multicolumn{2}{|c|}{ Older Children } & \multicolumn{2}{|c|}{ Adults } \\
\hline & $M$ & $S E$ & $M$ & $S E$ & $M$ & $S E$ \\
\hline Photo & .63 & .10 & .56 & .09 & .15 & .03 \\
\hline Word & .70 & .11 & .43 & .08 & .18 & .04 \\
\hline Together & .67 & .07 & .50 & .06 & .16 & .02 \\
\hline
\end{tabular}


as a three-way interaction $[F(12,180)=2.47, p<.05]$, were found. More specific analyses at single electrodes were conducted and revealed a reliable old/new effect at P3 and PZ only for old target items, but not for false alarms to nontargets at any electrode side, with the exception of a negative-going old/new effect at $\mathrm{C} 4$.

The observation that the parietal old/new effect with children was obtained neither for misses nor for erroneous old responses (false alarms) resembles that of the functional characteristics of the adult's parietal old/new effect (Friedman \& Johnson, 2000). Given this, we conclude that this effect is associated with recollection-based processes in children in a similar way as in adults.

\section{DISCUSSION}

The aim of this study was to investigate the relative contribution of familiarity and recollection to recognition memory across developmental stages by means of ERPs. Two groups of children and young adults studied photos and spoken words. At test, they were required to judge whether or not the corresponding line drawings depicted objects previously shown in the target source. Particular focus was placed on the ability to reject previously studied information from the nontarget source that differed during the study phase in several respects: in modality and order of presentation, as well as in the background color of the screen. Since nontargets and targets can be assumed to be familiar to a similar extent in the test phases, age-related changes in the use of recollection should be evident as an increased ability to differentiate between targets and nontargets. Consistent with this prediction, children of both age groups, but not adults, committed a large number of false alarms to old items from the nontarget source. In the ERPs, a parietal old/new effect, taken as the putative correlate of recollection-based processes, was found in older children, as well as in a subgroup of younger children with a comparable performance level. As was revealed by additional analyses conducted for misses and false alarms, the children's parietal old/new effect showed functional characteristics similar to those for adults.

In contrast, three distinct ERP old/new effects were revealed in the adult group: an early midfrontal old/new effect for both kinds of studied information was followed by a centroparietal old/new effect for targets only. Starting around $800 \mathrm{msec}$, a late right frontal old/new effect was found selectively for target hits. For adults, but not for children, old/new effects for nontargets varied as a function of target category; that is, they were found only for nontarget photos that were perceptually similar to the pictures used as retrieval cues.

\section{Behavioral Performance}

The present behavioral findings are in line with those in previous studies (Billingsley et al., 2002; Cycowicz et al., 2003; Cycowicz et al., 2001). In the present study, the performance in the target word condition proved to be lower than that in the target photo condition. This effect was reliable for both the older and the younger children, but not for the adults. The mnemonic advantage of pictures over words ( picture superiority effect) is considered to be a consequence of greater elaboration of pictorial information (e.g., Vaidya \& Gabrieli, 2000). When in doubt, the adults may have retrieved the nontargets (i.e., photos) to reject the possibility that a given item was presented in the target context (i.e., recall to reject; Clark, 1992). These strategic processes may have increased the adults' task performance in the target word condition and, by this, may have wiped out the picture superiority effect. Whereas the behavioral data do not give conclusive evidence for this hypothesis, the analysis of target and nontarget ERP waveforms allows a test of this assumption directly (see the discussion of the ERP results below). During an exclusion task, essentially two decisions need to be translated into one motor response: First, new items need to be separated from those studied before, and then the more difficult decision between old targets and nontargets is made. Therefore, memory performance was specified separately with respect to new and nontarget items. Although the performance level corrected for false alarms to new items [i.e., $\operatorname{Pr}($ item)] showed a definite increase as a function of age, this increase in accuracy was even larger when false alarms to nontargets were taken into account $[\operatorname{Pr}($ source) $]$. This pattern of results confirms the view that children's source memory performance has been overestimated in previous studies that did not take false alarms to nontargets into account. These intrusion errors to the critical nontargets not only are a very common type of error (Simons et al., 2002), but also form part of the distinction between two sources of information and, thus, tap one of the defining aspects of source memory.

However, another factor might contribute to the general overestimation of source memory performance during exclusion tasks, particularly when the accuracy during item recognition is low. Due to the nature of the exclusion task, new items and old nontarget items receive the same response. Thus, it is impossible to distinguish correct responses to nontarget items from misclassifications of nontargets as new items (i.e., misses). Post hoc tests for ERPs to misses confirmed this view, since the children's ERP waveforms for correct rejections of nontargets were statistically undistinguishable from the waveforms elicited by misses.

When nontarget forgetting is taken into account for the behavioral performance, the observed performance difference between the age groups increases dramatically: The estimates for the false alarm rate to nontargets when the participants actually remembered the item's previous occurrence was $67 \%$ for young children, as compared with $50 \%$ for older children and $16 \%$ for young adults. In accordance with previous findings (e.g., Cycowicz et al., 2001), the increase in source memory abilities with increasing age was statistically independent from the observed increase in item memory. 


\section{ERP Old/New Effects for Targets and Nontargets at Parietal Electrode Sites}

In all age groups, a parietal old/new effect was observed for the target hits. However, for the youngest age group, the effect was statistically reliable only when the performance level was sufficiently high, after the 5 lowest performers had been excluded from the analysis. In both groups of children, the old/new effect had the typical left-parietal topography, whereas for adults, it was more centro-parietally distributed, with a maximum at the vertex and right central electrodes, presumably reflecting an overlap of the parietal old/new effect and the early portion of the right frontal old/new effect.

The fact that the parietal old/new effect in children was absent for misses and false alarms and, by this, showed functional characteristics similar to those for adults suggests that it may be associated with recollection-based processes, irrespective of age group. An objection to this account could be that, rather than being associated with recollection, the parietal old/new effect in children may be a reflection of a perceptual matching between study and test materials. However, even though the children remembered photos better than spoken words, as reflected by their picture superiority effect, the size of the parietal old/new effect was not modulated by the similarity between study and test materials. In fact, as is illustrated in Figure 7, showing the old/new effects for both target types, the target old/new effect at parietal recordings was not significantly different for target photos and target words, for which a perceptual matching strategy was impossible. Even though the latter analysis was restricted to the children who had performed well and was collapsed across both children groups, it does not support a perceptual matching account for the parietal old/new effect. In light of these results, it is reasonable to assume that even though the hit rates were lower for the children than for the adults, the children's few hit responses were mediated by recollection.

Whereas both groups of children failed to show old/ new effects for nontargets, these items elicited an effect similar to the target old/new effect in the adult group, albeit smaller in size. This finding is in accordance with previous work reporting a smaller parietal old/new effect for nontarget than for target items: Wilding and Rugg (1997) argued that a larger proportion of correctly classified nontarget items than target items was not accompanied by recollection, since it was not necessary to retrieve the source information of nontarget items.

Interestingly, in the present study, the retrieval of nontarget information by adults was modulated by the target category, in that nontarget old/new effects were obtained only for photos - that is, in the subgroup of adults that had to retrieve studied words as targets. No such old/new effects were found for the children. A corresponding finding was reported by Herron and Rugg (2003). In their study, participants studied visually presented words and pictures. In two subsequent exclusion tasks with words as retrieval cues, they had to retrieve either words or pic- tures. Target accuracy was lower when pictures were targets, rather than words. The ERPs revealed a differential pattern of target and nontarget old/new effects as a function of target category. When pictures were the target category, a similar parietal old/new effect was seen for target pictures and nontarget words. However, when words were targets, nontarget pictures failed to elicit a reliable old/ new effect. The authors argued that the two target groups differed in the amount of nontarget source information activated during retrieval of target information as a function of similarity between test cue and nontarget. Only if this similarity is high, as in the case of studied words and words as retrieval cues, nontarget would be recalled along with the targets. Similar to the findings described above, in the present study the size of the nontarget old/new effect for the adults seemed to vary according to the target status. The difference in the magnitude of the nontarget old/new effects for photos or words can be explained as a function of target specificity. As the visual features of the test items (line drawings) more closely resembled the study photos than the auditorily presented words, it is possible that retrieval of the nontarget photos was more easily activated by the test items in a bottom-up way than in the case of nontarget words that did not share any perceptual features with the test cues.

Alternatively, the adults in the target word group may have deliberately recalled items from both contexts and only subsequently differentiated between targets and nontargets. Such a recall to reject strategy is beneficial for performance when only some target items, but at least as many nontarget items, can be recalled. By trying to place every item into its study context when in doubt, it is possible to enhance source memory performance at the mere "cost" of retrieving source information that is not asked for (see also Wilding \& Sharpe, 2004). The fact that the adults' source memory performance was highly similar for both target groups and, by this, the picture superiority effect present in the children data was not exhibited supports the view that the adults in the target word group used this particular strategy to enhance their memory performance for words.

It remains an open issue whether the retrieval of nontarget information is due to an automatic and bottom-up reactivation of the study context because of the perceptual similarity between study and test items or, rather, to a topdown recall to reject strategy. While the study words were identical to the test cues used in Herron and Rugg's (2003) study, the similarity was restricted to only some visual features in the present study, thus making an automatic reactivation of perceptual features less likely. Furthermore, it is unlikely that the automatic reactivation of perceptual features should differ as a function of age. If anything, the children's stronger focus on perceptual details at the cost of conceptual elaboration would argue for a stronger reactivation of these features in children. The fact that the retrieval of nontarget photos was paralleled by enhanced performance in the target word group in adults favors a strategic account. Following this line of argumentation, 
the lack of strategic control over the retrieval of nontargets by children, as evident in a large picture superiority effect, as well as in the absence of an ERP old/new effect for nontargets, could be held responsible for the particularly poor performance in the target word groups of children.

\section{ERP Old/New Effects at Frontal Recording Sites}

In the group of adults, two distinct frontal components were identified in the present study that were absent in both groups of children. First, an early midfrontal component was evident between 200 and $400 \mathrm{msec}$ for both target and nontarget items. Given that this effect was independent of the target status of studied items and dissociable from the parietal component, it corresponds well to the proposed functional significance of a familiarity component (see Curran, 2000; Friedman \& Johnson, 2000; Mecklinger, 2000). Furthermore, it proved to be sensitive to repetition, even in the absence of the repetition of perceptual features between study and test phases. This finding corresponds very well to the proposed view that the midfrontal old/new effect reflects an amodal familiarity component (Curran \& Cleary, 2003; Curran \& Dien, 2003). In contrast to this and contrary to expectations, both groups of children did not show any reliable frontal modulation preceding the parietal old/new effect. It could be argued that the lower number of trials entering the children's ERPs and the fact that some children had to be excluded from the analyses, due to low performance levels, may have lowered the statistical power and, by this, the likelihood of finding these effects in children. However, since we found reliable ERP effects at parietal recordings with the same testing conditions, we consider this objection as rather unlikely.

Despite children's high numbers of false alarms to nontargets, neither target hits nor correct rejections of nontargets elicited an old/new difference similar to the midfrontal old/new effect for adults. Several reasons may account for this null result. One corresponds closely to the argument, given above, that a high proportion of the correct rejection of nontargets by children represent misses and should elicit a much smaller familiarity response. Second, it is conceivable that the lack of the early midfrontal effect in fact does reflect differential processes by which children and adults solve this task. Whereas adults rely predominantly on conceptual processing, children have been reported to focus more on perceptual features of stimuli to be remembered (Friedman, 1992; see also Hayes \& Heit, 2004). Applying this strategy in the present task would not be successful, since the similarity between study and test items could be assessed only on the conceptual level. According to this argumentation, the process of familiarity would continue to develop during middle and late childhood from a more perceptually oriented into a more conceptual and amodal memory system.

A similar picture emerges for the late right frontal old/ new effect. It is found only in adults and is restricted to target hits starting at around $700 \mathrm{msec}$. The fact that this modulation was found only for targets in the present study is consistent with previous reports (e.g., Wilding \& Rugg,
1997), as well as with the interpretation of strategic processes that operate on the results of successful memory retrieval and, therefore, vary with target status (see Wilding \& Rugg, 1997).

Since this component is more closely related to strategic processing such as the verification and monitoring of retrieved memory contents, its absence in children is less surprising. In fact, these processes can be conceived as a prefrontal control mechanism responsible for criterion setting and continuous reevaluation of the chosen criterion (Dobbins et al., 2004; Ranganath, 2004). A deficiency in such a prefrontal control system might impede the fast assessment of various levels of relative familiarity, since it could not adapt flexibly to the demands of the task at hand. This deficit in prefrontal control mechanism may have resulted in less flexible and less task-adapted retrieval strategies in which recollection of target information, but not other sources, can be used in pursuit of accurate task performance.

\section{Conclusion and Open Issues}

In the present study, a clear increase in memory performance accuracy was seen with increasing age. It was most pronounced in children's high number of false alarms to nontarget items and, presumably, was related to the lack of control processes housed by the PFC that guide memory retrieval (e.g., Dobbins et al., 2002) and continue to develop during middle and late childhood years (Sowell et al., 2001). In accord with prior ERP studies on source memory (e.g., Cycowicz et al., 2003; Johansson \& Mecklinger, 2003; Wilding \& Rugg, 1996), three ERP components related to separate subprocesses of memory retrieval could be identified in the adults: an early midfrontal old/new effect that proved to be sensitive to repetition, but not to target status; a centro-parietal old/new effect for targets and, to a lesser extent, for nontargets; and a late right frontal old/new effect that was evident for targets only. The centro-parietal old/new effect to nontargets varied according to target status: Only photos to be rejected as nontargets elicited an old/new effect similar to the one observed for targets. This presumably reflects a strategic modulation of source memory retrieval - that is, the adoption of a deliberate recall to reject strategy.

The parietal old/new effect to targets that was observed in children's ERPs and the absence of this effect to misses and nontargets supports the interpretation that the few successfully retrieved target hits were based on recollection. It remains to be investigated whether the absence of an early midfrontal old/new effect in the present study was due to the lack of perceptual similarity between study and test items or whether familiarity-based decisions rely on postretrieval monitoring and frontal control processes that are not fully developed in this age group.

This pattern of results implies that adults, in contrast to children, can flexibly make use of multiple informational sources for successful item and source retrieval and, under conditions of high retrieval demands, are also able to use the test cue information to strategically search 
nontarget information in memory to enhance memory performance.

Despite poorer memory performance, the children showed a parietal old/new effects taken as a correlate of recollection. No ERP indices of familiarity-based recognition memory control processes were obtained. This may suggest that the reinstatement of target information acquired in a specific context (and mediated by recollection) precedes the maturation of memory control processes that are responsible for the specification of retrieval task parameters and allow us to distinguish between several sources of information.

\section{REFERENCES}

Billingsley, R. L., Smith, M. L., \& McAndrews, M. P. (2002). Developmental patterns in priming and familiarity in explicit recollection. Journal of Experimental Child Psychology, 82, 251-277.

Chapman, L. J., Chapman, J. P., Curran, T. E., \& Miller, M. B. (1994). Do children and the elderly show heightened semantic priming? How to answer the question. Developmental Review, 14, 159185.

Clark, S. E. (1992). Word frequency effects in associative and item recognition. Memory \& Cognition, 20, 231-243.

Curran, T. (2000). Brain potentials of recollection and familiarity. Memory \& Cognition, 28, 923-938.

Curran, T., \& Cleary, A. M. (2003). Using ERPs to dissociate recollection from familiarity in picture recognition. Cognitive Brain Research, 15, 191-205.

Curran, T., \& Dien, J. (2003). Differentiating amodal familiarity from modality-specific memory processes: An ERP study. Psychophysiology, 40, 979-988.

Cycowicz, Y. M. (2000). Memory development and event-related brain potentials in children. Biological Psychology, 54, 145-174.

Cycowicz, Y. M., Friedman, D., \& Duff, M. (2003). Pictures and their colors: What do children remember? Journal of Cognitive Neuroscience, 15, 759-768.

Cycowicz, Y. M., Friedman, D., Duff, M., \& Snodgrass, J. G. (2001). Recognition and source memory for pictures in children and adults. Neuropsychologia, 39, 255-267.

Cycowicz, Y. M., Friedman, D., Rothstein, M., \& Snodgrass, J. G. (1997). Picture naming by young children: Norms for name agreement, familiarity, and visual complexity. Journal of Experimental Child Psychology, 65, 171-237.

Czernochowski, D., Brinkmann, M., Mecklinger, A., \& JohansSON, M. (2004). When binding matters: An ERP analysis of the development of recollection and familiarity. In A. Mecklinger, H. Zimmer, \& U. Lindenberger (Eds.), Bound in memory: Insights from behavioral and neuropsychological studies (pp. 93-128). Aachen: Shaker.

Dobbins, I. G., Foley, H., Schacter, D. L., \& Wagner, A. D. (2002). Executive control during episodic retrieval: Multiple prefrontal processes subserve source memory. Neuron, 35, 989-996.

Dobbins, I. G., Simons, J. S., \& Schacter, D. L. (2004). fMRI evidence for separable and lateralized prefrontal memory monitoring processes. Journal of Cognitive Neuroscience, 16, 908-920.

Dywan, J., Segalowitz, S. J., \& Arsenault, A. (2002). Electrophysiological response during source memory decisions in older and younger adults. Brain \& Cognition, 49, 322-340.

Dywan, J., Segalowitz, S. J., \& WebSter, L. (1998). Source monitoring: ERP evidence for greater reactivity to nontarget information in older adults. Brain \& Cognition, 36, 390-430.

Dywan, J., Segalowitz, S. J., Webster, L., Hendry, K., \& Harding, J. (2001). Event-related potential evidence for age-related differences in attentional allocation during a source monitoring task. Developmental Neuropsychology, 19, 99-120.

Friedman, D. (1992). Event-related potential investigations of cognitive development and aging. In D. Friedman \& G. Bruder (Eds.), Psychophysiology and experimental psychopathology: A tribute to Samuel
Sutton (Annals of the New York Academy of Sciences, Vol. 658, pp. 33-64). New York: New York Academy of Sciences.

FrIEDMAN, D. (2000). Event-related brain potential investigation of memory and aging. Biological Psychology, 54, 175-206.

Friedman, D., \& Johnson, R., JR. (2000). Event-related potential (ERP) studies of memory encoding and retrieval: A selective review. Microscopy Research \& Technique, 51, 6-28.

Gathercole, S. E. (1998). The development of memory. Journal of Child Psychology \& Psychiatry, 39, 3-27.

Giles, J. W., Gopnik, A., \& Heyman, G. D. (2002). Source monitoring reduces the suggestibility of preschool children. Psychological Science, 13, 288-291.

Gratton, G., Coles, M. G. H., \& Donchin, E. (1983). A new method for off-line removal of ocular artifact. Electroencephalography \& Clinical Neurophysiology, 55, 468-484

HAYES, B., \& HeIT, E. (2004). Why learning and development can lead to poorer recognition memory. Trends in Cognitive Sciences, 8, 337-339.

HERron, J. E., \& RUGG, M. (2003). Retrieval orientation and the control of recollection. Journal of Cognitive Neuroscience, 15, 843-854.

JACOBY, L. (1991). A process dissociation framework: Separating automatic from intentional uses of memory. Journal of Memory \& Language, 30, 513-541.

JOHANSSON, M., \& MeCKLINGER, A. (2003). The late posterior negativity in ERP studies of episodic memory: Action monitoring and retrieval of item attribute conjunctions. Biological Psychology, 64, 91-117.

Johnson, M., Hashtroudi, S., \& Lindsay, D. S. (1993). Source monitoring. Psychological Bulletin, 114, 3-28.

KePpel, G., \& Wickens, T. D. (2004). Design and analysis: A researcher's handbook. Upper Saddle River, NJ: Prentice-Hall.

Marshall, D. H., Drummey, A. B., Fox, N. A., \& Newcombe, N. S. (2002). An event-related potential study of item recognition memory in children and adults. Journal of Cognition \& Development, 3, 201-224.

Mayes, A. R., Holdstock, J. S., Isaac, C. L., Hunkin, N. M., \& RobERTS, N. (2002). Relative sparing of item recognition memory in a patient with adult-onset damage limited to the hippocampus. Hippocampus, 12, 325-340.

MeCKLINGer, A. (2000). Interfacing mind and brain: A neurocognitive model of recognition memory. Psychophysiology, 37, 565-582.

Mecklinger, A., von Cramon, D. Y., \& Matthes-von Cramon, G. (1998). Event-related potential evidence for a specific recognition memory deficit in adult survivors of cerebral hypoxia. Brain, 121, 1919-1935.

Moscovitch, M. (1995). Models of consciousness and memory. In M. S. Gazzaniga (Ed.), The cognitive neurosciences (pp. 1341-1356). Cambridge, MA: MIT Press.

Nessler, D., Mecklinger, A., \& Penney, T. B. (2001). Event related brain potentials and illusory memories: The effects of differential encoding. Cognitive Brain Research, 10, 283-301.

Nessler, D., Mecklinger, A., \& Penney, T. B. (2005). Perceptual fluency, semantic familiarity, and recognition-related familiarity: An eletrophysiological exploration. Cognitive Brain Research, 22, 265-288.

Nolde, S. F., Johnson, M. K., \& RAYE, C. L. (1998). The role of prefrontal cortex during tests of episodic memory. Trends in Cognitive Sciences, 2, 399-406.

O'NeILl, D. K., \& GopNIK, A. (1991). Young children's ability to identify the sources of their beliefs. Developmental Psychology, 27, 390-397.

RANGanath, C. (2004). The 3-D prefrontal cortex: Hemispheric asymmetries in prefrontal activity and their relation to memory retrieval processes. Journal of Cognitive Neuroscience, 16, 903-907.

Ranganath, C., \& Paller, K. A. (1999). Frontal brain potentials during recognition are modulated by requirements to retrieve perceptual detail. Neuron, 22, 605-613.

Ranganath, C., \& Paller, K. A. (2000). Neural correlates of memory retrieval and evaluation. Cognitive Brain Research, 9, 209-222.

RoEbers, C. M. (2002). Confidence judgments in children's and adults' event recall and suggestibility. Developmental Psychology, 38, 10521067.

Roebers, C. M., \& Howie, P. (2003). Confidence judgments in event recall: Developmental progression in the impact of question format. Journal of Experimental Child Psychology, 85, 352-371.

Ruffman, T., Rustin, C., Garnham, W., \& Parkin, A. (2001). Source 
monitoring and false memories in children: Relation to certainty and executive functioning. Journal of Experimental Child Psychology, 80, 95-111.

RugG, M. D., Mark, R. E., Walla, P., Schloerscheidt, A. M., Birch, C. S., \& Allan, K. (1998). Dissociation of the neural correlates of implicit and explicit memory. Nature, 392, 595-598.

SCHNider, A. (2003). Spontaneous confabulation and the adaptation of thought to ongoing reality. Nature Reviews Neuroscience, 4, 662-671.

Shimamura, A. (2002). Memory retrieval and executive control processes. In D. T. Stuss \& R. T. Knight (Eds.), Principles of frontal lobe function (pp. 210-220). New York: Oxford University Press.

Simons, J. S., \& Spiers, H. J. (2003). Prefrontal and medial temporal lobe interactions in long-term memory. Nature Reviews Neuroscience, 4, 637-648.

Simons, J. S., Verfaellie, M., Galton, C. J., Miller, B. L., Hodges, J. R., \& Graham, K. S. (2002). Recollection-based memory in frontotemporal dementia: Implications for theories of long-term memory. Brain, 125, 2523-2536.

Smith, M. E., \& Halgren, E. (1989). Dissociations of recognition memory components following temporal lobe lesions. Journal of Experimental Psychology: Learning, Memory, \& Cognition, 15, 50-60.

SNODGrass, J. G., \& CoRwin, J. (1988). Pragmatics of measuring recognition memory: Applications to dementia and amnesia. Journal of Experimental Psychology: General, 117, 34-50.

Snodgrass, J. G., \& VANDERWART, M. (1980). A standardized set of 260 pictures: Norms for name agreement, image agreement, familiarity, and visual complexity. Journal of Experimental Psychology: Human Learning \& Memory, 6, 174-215.

Sowell, E., Delis, D., Stiles, J., \& Jernigan, T. (2001). Improved memory functioning and frontal lobe maturation between childhood and adolescence. Journal of the International Neuropsychological Society, 7, 312-322.

Trott, C. T., Friedman, D., Ritter, W., Fabiani, M., \& Snodgrass, J. G. (1999). Episodic priming and memory for temporal source: Event-related potentials reveal age-related differences in prefrontal functioning. Psychology \& Aging, 14, 390-413.

Tulving, E. (1985). Memory and consciousness. Canadian Psychology, 26, 1-12.

VAIDYA, C. J., \& Gabrieli, J. D. E. (2000). Picture superiority in conceptual memory: Dissociative effects of encoding and retrieval tasks. Memory \& Cognition, 28, 1165-1172.

WAGNER, A. (2002). Cognitive control and episodic memory: Contributions from prefrontal cortex. In L. Squire \& D. Schacter (Eds.), Neuropsychology of memory (pp. 174-192). New York: Guilford.

WILDING, E. L. (2000). In what way does the parietal ERP old/new ef- fect index recollection? International Journal of Psychophysiology, 35, 81-87.

WILDING, E. L., \& RUGG, M. D. (1996). An event-related potential study of recognition memory with and without retrieval of source. Brain, 119, 889-905.

WILDING, E. L., \& RUGG, M. D. (1997). Event-related potentials and the recognition memory exclusion task. Neuropsychologia, 35, 119-128.

Wilding, E. L., \& Sharpe, H. (2004). The influence of response-time demands on electrophysiological correlates of successful episodic retrieval. Cognitive Brain Research, 18, 185-195.

Yonelinas, A. P. (2002). The nature of recollection and familiarity: A review of 30 years of research. Journal of Memory \& Language, 46, 441-517.

Yovel, G., \& Paller, K. A. (2004). The neural basis of the butcher-onthe-bus phenomenon: When a face seems familiar but is not remembered. NeuroImage, 21, 789-800.

\section{NOTES}

1. Several additional participants (17 young and 6 older children) had to be excluded from further analyses because we could not obtain a sufficient number of artifact-free ERP trials. This was the result of a combination of low performance levels and excessive movement artifacts. Five adult subjects were excluded because of technical problems during data collection. One adult was excluded because of an extremely low performance level.

2. To decide which items were suitable to use for a group of young children whose native language is German, the original Snodgrass and Vanderwart (Cycowicz, Friedman, Rothstein, \& Snodgrass, 1997; Snodgrass \& Vanderwart, 1980) black-and-white line drawings were rated, in a pretest, by children 5-6 years of age recruited from a local kindergarten. The children were asked whether they knew the object in the picture and were asked to give the name of the object, if possible. Only those pictures that all the children recognized and that a majority spontaneously gave the same label to were used. Thirty additional items were retained as practice items.

3 . Since longer overall latencies may be correlated with larger difference scores when two response categories that vary in latencies are compared (Chapman, Chapman, Curran, \& Miller, 1994), we also used a logarithmic transformation of reaction times for these analyses. The pattern of results did not change for either targets or nontargets, as compared with new items.

(Manuscript received November 10, 2004; revision accepted for publication July 7,2005 .) 